\title{
Computational Modeling of Grain Growth in Self-Reinforced Silicon Nitride
}

\author{
Yusuke OKAMOTO, Naoto HIROSAKI and Hideaki MATSUBARA \\ Synergy Ceramics Laboratory, Fine Ceramics Research Association, 2-4-1, Mutsuno, Atsuta-ku, Nagoya-shi 456-8587 \\ 自己複合化窒化ケイ素の粒成長挙動の計算機モデル化 \\ 岡本裕介・広崎尚登・松原秀彰 \\ ファインセラミックス技術研究組合シナジーセラミックス研究所, 456-8587 名古屋市熱田区六野 2-4-1
}

\begin{abstract}
A model is proposed for studying grain growth in silicon nitride by computer simulation. The simulation is based on the Monte Carlo method and uses the Potts model with additional features peculiar to silicon nitride ceramics, such as anisotropy of grain boundary energies and the presence of liquid phase. The simulation successfully produced self-reinforced microstructures. It was found that the self-reinforcement phenomenon occurred only within a particular range of liquid phase fractions. The influence of anisotropy in interface energy on inhomogeneous grain growth was also examined. When interface energies are isotropic, the microstructure was essentially homogeneous. The results of these simulations suggest that anisotropy in interface energy and the presence of an appropriate amount of liquid phase are two important factors controlling the self-reinforcement process in silicon nitride materials.
\end{abstract}

[Received June 29, 1998; Accepted December 3, 1998]

Key-words : Computer simulation, Silicon nitride, Grain growth, Self-reinforcement

\section{Introduction}

The typical microstructure of silicon nitride ceramics consists of small equiaxed grains as the matrix and large elongated grains as the toughening phase. ${ }^{1)-5)}$ The elongated grains develop during the sintering process as a result of inhomogeneous growth of several grains. This behavior of silicon nitride is often referred to as "self-reinforcement" or "in-situ toughening." Although the phenomenon itself is well-known, the mechanism of inhomogeneous grain growth are still not clearly understood.

Abnormal grain growth of polycrystalline materials has been studied for more than 30 years. Hillert formulated a quantitative expression of abnormal grain growth assuming the influence of second phase particles. ${ }^{6}$ ) Hillert's theory holds true for many materials systems, but it does not apply to silicon nitride. Ordinary silicon nitride is composed only of silicon nitride grains and a glassy grain boundary phase, no second phase particle is involved. As far as silicon nitride is concerned, there has been little progress in the theory of grain growth, because it is extremely difficult to apply analytical approaches to this material. This is due to strong anisotropy in the grain shape and the complicated distribution of liquid phase involving triple junctions and thin films.

One of the alternative approaches for studying grain growth is computational simulation. Anderson et al. have proposed the Potts model for grain growth simulation based on the Monte Carlo technique, ${ }^{7), 8)}$ and many researchers have followed their method in investigation of grain growth behavior. ${ }^{9)-12)}$ Owing to its simple calculation scheme, this technique can be applied even to complicated materials systems, for example, those with anisotropic interface energy, ${ }^{11)}$ the presence of pores ${ }^{9), 10)}$ and recrystallization. ${ }^{13), 14)}$ A grain growth model with a liquid phase, which is one of the most significant factors for microstructure development, has been proposed by Matsubara and Brook, who suggested the random walk process. ${ }^{15)}$ This model has shown good agreement with the grain growth behavior of actual aluminum nitride. ${ }^{16)}$

As for abnormal grain growth, a number of analyses have been performed with the Potts model. Calculations made by Rollett et al. were the first attempt to simulate and analyze abnormal grain growth behavior, ${ }^{17)}$ and Grest et al. extend- ed them to three dimensions. ${ }^{18)}$ They assigned various levels of interface energy and grain boundary mobility according to the type of the interface. Kunaver and Kolar studied grain growth behavior based on the introduction of anisotropy in grain boundary energy for several selected grains in the matrix. ${ }^{11)}$ These simulations have successfully produced microstructures with bimodal grain size distributions, which agreed well with certain material systems. However, the simulation results have disagreed in several respects with actual silicon nitride materials. It seems unnatural to select several grains that grow "preferentially" in silicon nitride. For example, in the case of seeded silicon nitride, both the area fraction and density of abnormally grown grains were simultaneously proportional to the initial amount of seed particles. ${ }^{19)}$ This implies that the origin of preferential grain growth in silicon nitride is not "special" grains, but large grains. Thus, other kinetics should be assumed to explain the self-reinforcement process of silicon nitride. We suspect that the presence of liquid phase and anisotropic interface energies play an important role in the self-reinforcement process.

The purpose of this work is to construct a simulation model which represents the grain growth behavior of silicon nitride and to investigate the mechanisms of the selfreinforcement phenomenon, and to establish this technique as an efficient microstructure design tool for ceramics.

\section{Simulation methodology}

2.1 Calculation sequence

The grain growth simulation was carried out on a 2dimensional triangular lattice on the basis of the Potts mode. ${ }^{17)}$ A lattice of 500 by 500 cells was prepared and periodic boundary conditions were imposed. For each cell, orientation numbers $(Q)$, ranging from 1 to 64 were distributed at random. Cells with these numbers correspond to the solid phase. A cluster of cells consisting of those having the same orientation number was regarded as a single grain. At several sites in the lattice, a cell with an orientation number of 0 was specified to represent liquid phase (Fig. 1(A)). A cluster of liquid phase cells was regarded as a liquid phase pocket of the actual material.

Interface energy is a significant factor governing 
(A)

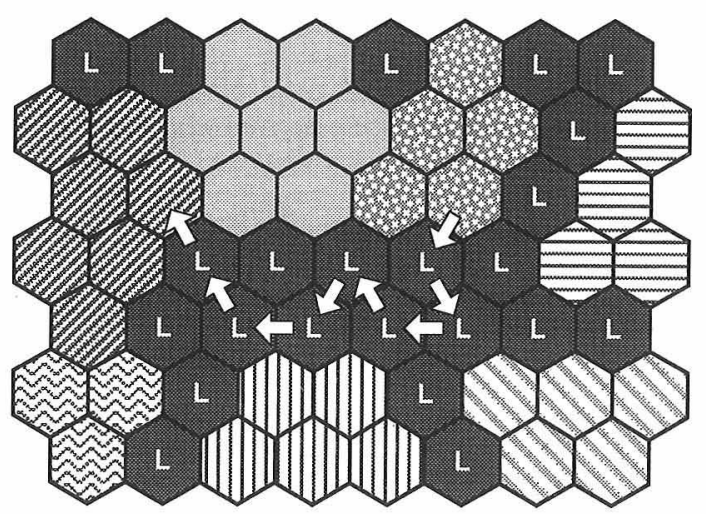

L: Liquid phase

(B)

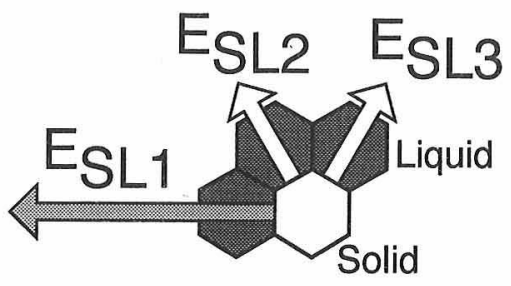

Fig. 1. Calculation model used in this study. (A) The diffusion process is represented by a random walk. The random walk is performed until it hits any solid cell. (B) Anisotropic interface energies are introduced for three interfaces of each solid cell.

microstructure development, because the driving force of grain growth is the reduction of the total interfacial energy. In this simulation, interface energies were assigned in the following manner. When two adjacent cells had different orientation numbers, an interface energy was assigned between them. The value of the interface energy depended on the type of interface. For a solid to solid interface, energy $E_{\mathrm{SS}}$ was assigned irrespective of the orientation numbers of either side. In the present simulation, $E_{\mathrm{SS}}$ was taken as unity. It should be noted that in actual silicon nitride these interfaces may contain an intergranular phase, ${ }^{20), 21)}$ although the interfaces in this model were represented as solid to solid interfaces. For a liquid to solid interface, various interface energies were assigned according to the face of the solid cell. Since a triangular lattice was employed, each cell had six faces in three directions. Higher energy $E_{\mathrm{SL} 1}$ was assigned in one direction, and lower energies $E_{\mathrm{SL} 2}$ and $E_{\mathrm{SL} 3}$ were assigned to the other two directions (Fig. 1(B)). The direction of $E_{\mathrm{SL} 1}$ was determined according to the orientation number of the individual grain.

Mass transport was simulated using the following algorithm: Diffusion of solute species through liquid phase was expressed in terms of a random walk of a solid cell through liquid cells, ${ }^{15)}$ as illustrated in Fig. 1(A). The calculation procedure consisted of a series attempts to redistribute orientation numbers followed by judgment of success or failure based on the calculated total energy change.

The calculation proceeds as follows:

(1) A cell is selected at random from the lattice.

(2) If the selected cell is a liquid phase cell $(Q=0)$;

(i) and if all neighboring cells are liquid phase cells, then no redistribution is performed and the calculation returns to step (1).

(ii) and if one or more neighboring solid cells exist, the orientation number of the selected liquid cell is changed to the number of one of the neighboring solid cells. Next, a random walk from the position of the selected cell through the liquid phase is performed until it hits any solid cell, and the solid cell that is hit is changed to a liquid cell. The calculation then proceeds to step (4).

(3) If the selected cell is a solid phase cell;

(i) and if all neighboring cells are solid phase cells, the orientation number $Q$ is changed to the number of one of the neighboring cells. The calculation flow proceeds to step (4).

(ii) and if one or more neighboring liquid cells exist, the selected cell is changed to a liquid cell, and a random walk is performed from the position of the selected cell through the liquid phase until it hits any solid cell. Next, the cell of the preceding position just before the hit is changed to a solid cell having the same orientation number as the one that was hit. The calculation continues with step (4).

(4) Finally, the total energy change $\Delta E$ resulting from the substitution (orientation and/or position) is calculated, and if $\Delta E$ equals zero or less, the substitution is successful, otherwise it is not. The calculation returns to step (1).

This procedure was repeated for a large number of cycles. The time scale used in the simulation was measured in terms of Monte Carlo steps (MCS) . ${ }^{7)}$ One MCS is defined as $N$ attempts (selection of a cell from the lattice) of the above redistribution irrespective of success of failure, where $N$ is the number of the total lattice sites.

According to the above procedure, the orientation number of a newly precipitated cell is assigned based one of surrounding cells $((2-\mathrm{ii}),(3-\mathrm{i}, \mathrm{ii}))$. This procedure is thought to correspond to epitaxial growth through a solution-reprecipitation process. ${ }^{2), 5), 22)}$ Hereafter, we refer to the above sequence as "Mode I." However, the question of whether the properties of intergranular films are close to or far from those of liquid phase pockets is still a topic of discussion. In other words, it is not clear that the diffusion through an intergranular film is fast or slow compared to that through triple junctions. To examine the influence of diffusion through an intergranular film, the following sequence was also employed. This sequence is referred to as "Mode II."

In Mode II, the diffusion in the intergranular thin film is assumed to be slower than that in the triple junction. ${ }^{24)}$ In this model, the properties of the intergranular film are assumed to be considerably different from those of triple junctions, due to ordering of the structure by crystal lattices of grains on both sides. ${ }^{23}$ ) The difference in the calculation procedure appears in step (3-i), the orientation change for a cell surrounded by solid cells only. When Mode II is employed, the new orientation number $Q$ is selected at random (from 1 to 64 in this study). This procedure is the same method as in the Potts model. Our previous studies were carried out using Mode II. ${ }^{15), 16)}$

After the calculations were performed, the simulation results were visualized on a computer screen. The maximum width $\left(D_{\max }\right)$, minimum width $\left(D_{\min }\right)$ and area of each grain were measured using an image analysis program (NIH Image 1.57, by Wayne Rasband).

\subsection{Calculation conditions}

In the present calculations, much attention was paid to the influence of liquid phase fraction and anisotropy in grain growth on microstructure development.

To examine the influence of liquid phase fraction, liquid phase cells were placed at random on the lattice. The liquid phase fraction 5, 10 and 20 area\% were chosen. The initial 
microstructures then underwent a preliminary calculation of $10 \mathrm{MCS}$ under the conditions of $E_{\mathrm{SL} 1}, E_{\mathrm{SL} 2}, E_{\mathrm{SL} 3}=\{0.5$, $0.5,0.5\}$ and Mode I. The preliminary calculation was performed because the grain shapes of the primitive microstructure were irregular and thought to be quite far from that of actual silicon nitride powder. After this calculation, the main calculation was started. In the main calculation, anisotropy in interface energy was introduced as $E_{\mathrm{SL} 1}$, $E_{\mathrm{SL} 2}, E_{\mathrm{SL} 3}=\{0.5,0.1,0.1\}$ using Mode I. The main calculation ran for 2,000 MCS under Mode I (or Mode II) and the microstructures were observed every $100 \mathrm{MCS}$.

The second question is the influence of anisotropy in interface energy. At a $10 \%$ liquid phase fraction, an initial microstructure was generated in the same manner. After 10 MCS preliminary calculation under Mode I, a simulation was performed under the isotropic condition $E_{\mathrm{SL} 1}, E_{\mathrm{SL} 2}$, $E_{\mathrm{SL} 3}=\{0.1,0.1,0.1\}$ and Mode I. The starting microstructure was completely identical with the anisotropic simulation of $10 \%$ liquid phase. The total number of calculation steps was $2000 \mathrm{MCS}$ and the observation interval was 100 MCS. The microstructure development was compared with that in the anisotropic case.

\section{Results and discussion}

\subsection{Influence of liquid phase fraction}

The microstructures varied greatly between different liquid phase fraction, after the same numbers of MCS, as shown in Fig. 2. Mode I was employed in this calculation. At $5 \%$ liquid phase fraction, the microstructures were homogeneous and only a few preferentially grown grains were observed (Fig. $2 / 5 \%$ ). In contrast, at $10 \%$ liquid phase fraction, a considerable number of grains grew preferentially and a self-reinforced structure was generated. Further, at 20\% liquid phase fraction, the microstructures became homogeneous. The grain size distributions summarized in Fig. 3 clearly reveal the difference between these microstructures. The grain size distribution for $5 \% \mathrm{li}$ quid phase fraction is sharp and has only one peak, as does the one for $20 \%$. In contrast, the distribution curve for the $10 \%$ liquid phase fraction is wider than those of 5 and $20 \%$ liquid phase fractions. Furthermore, in the distribution, at least two peaks are observed. The peak at around 40 cells corresponds to the large coarse grains. These results support the conclusion that in these calculations, self-reinforcement occurred only at $10 \%$ liquid phase fraction and not at 5 or $20 \%$.

This behavior agrees well with previously reported experimental results. The increase in the average grain diameter with an increasing additive amount have been observed in several experiments. Pyzik and Beaman have reported a gradual increase both in the length and diameter with an increase in the glass content from 4 to 15 mass $\% .{ }^{25}$ ) Although it is somewhat difficult to convert additive amounts to liquid phase fractions, considering the densities of each additive component, the mass fraction and volume fraction are thought to be close in value. Accordingly, the simulation results agreed well with the experimental results reported by Hwang et al. for an increase in additive amount

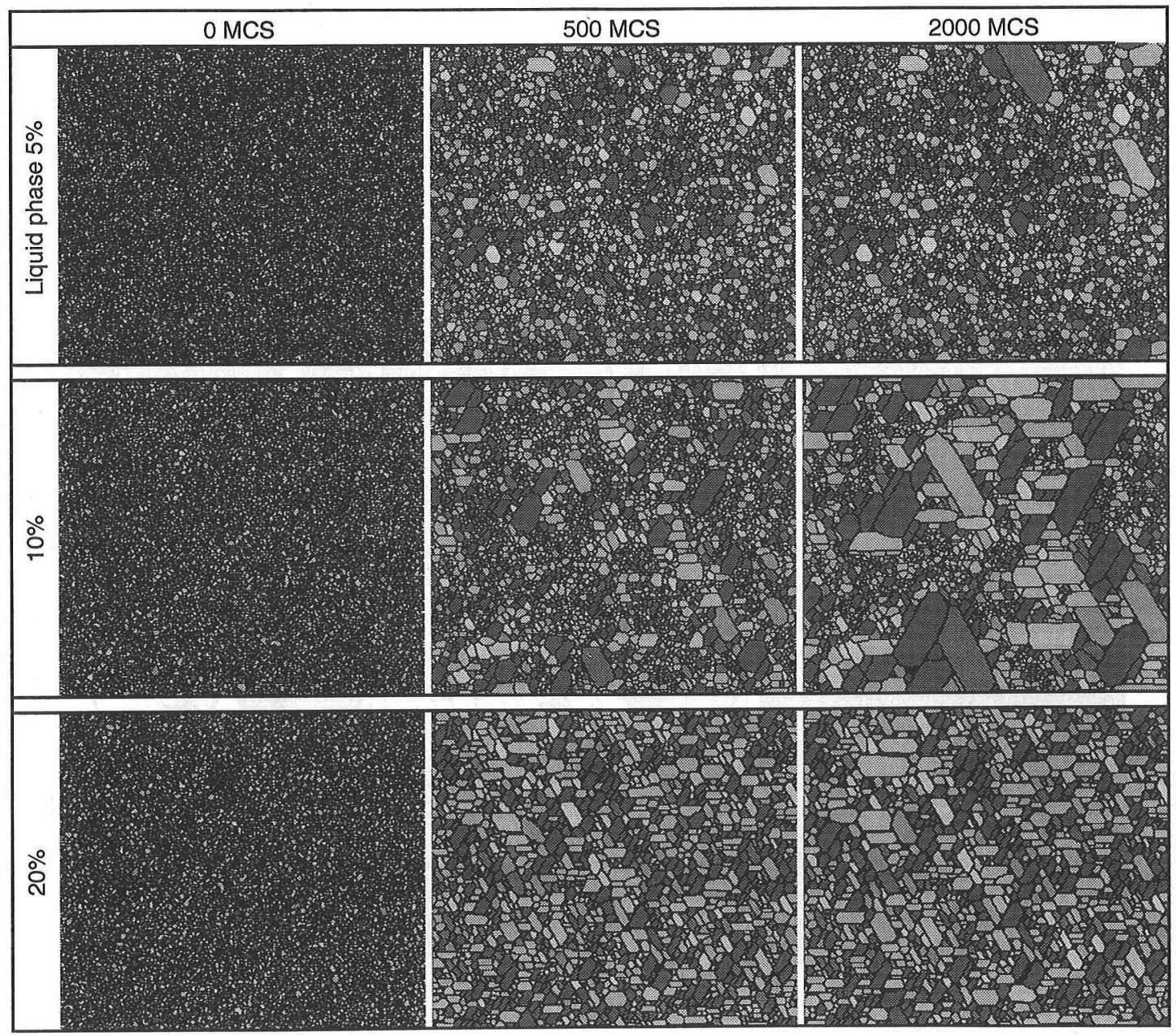

Fig. 2. Microstructures at various liquid phase fractions. In a particular range of liquid phase fractions, a self-reinforced microstructure is observed. In contrast, at an insufficient or excess fraction, the microstructures become relatively uniform. 


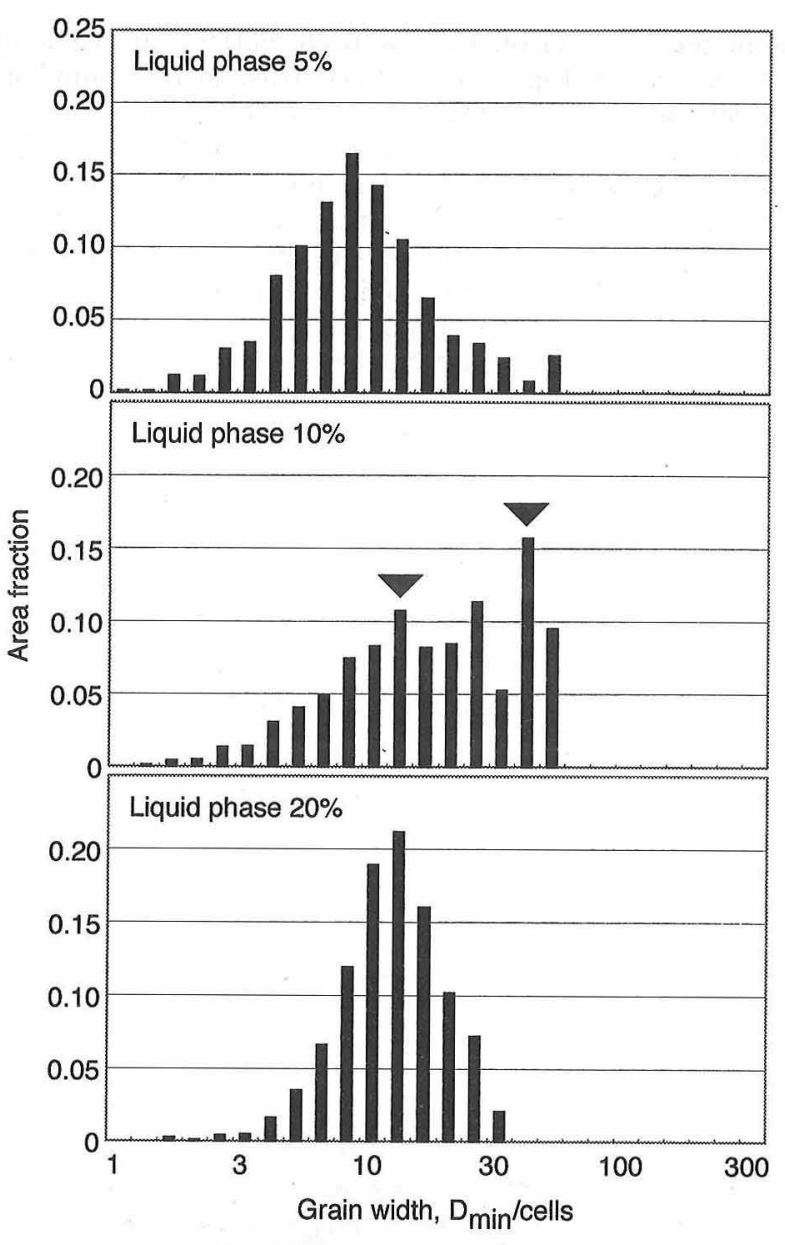

Fig. 3. Grain size distributions for liquid phase fractions 5, 10 and $20 \%$. Two peaks are observed in the distribution for $10 \%$. In contrast, only one peak appears in the distributions for 5 and $20 \%$ liquid phase fractions. from 2.5 to 10 mass $\%{ }^{26)}$

Hwang and Tien have also reported that (i) the grain size distribution became uniform for an excess amount of additive of 30 mass \% or more and (ii) with a smaller additive amount ( 2.5 mass $\%)$, the grain shape became equiaxed and the grain size distribution uniform. ${ }^{23)}$ This behavior also coincides with the results of the present study. Furthermore, Björklund et al. have reported grain growth behavior with a small amount of liquid phase. ${ }^{27)}$ They employed a glass-capsuled hot isostatic press technique to fabricate a specimen with no additive. The microstructure of the sample was uniform and the grain size was larger than that of a sample with 2.5 mass $\% \mathrm{Y}_{2} \mathrm{O}_{3}$ and 0.2 mass $\% \mathrm{Fe}_{2} \mathrm{O}_{3}$ additives.

We will now consider the mechanism of the self-reinforcement phenomenon in this simulation. The following mechanism are proposed. Once a grain begins to grow, a portion of liquid phase accumulates at the growth front. The accumulation accelerates the growth rate, and the grain gathers more liquid phase portions at the growth front in a particular range of liquid phase content. During one cycle of these steps, several grains grow preferentially to other matrix grains. In contrast, at an excess amount of liquid phase, such accumulation can not accelerate the growth rate, resulting in uniform microstructures.

To examine this hypothesis, additional calculations were performed using a smaller lattice (size: 100 by 100 cells). The calculation conditions were the same as the previous calculation, but the preliminary calculations (10 MCS) were omitted for simplicity and the main calculations started directly from the initial random microstructures. The results are illustrated in Fig. 4. The dark cells correspond to the liquid phase. Calculations 1 and 2 started from identical microstructures. In calculation 1, accumulation of liquid phase along a certain growth front was observed at around $500 \mathrm{MCS}$, as indicated by the circle. The large grain with the accumulated liquid phase cells along its growth front began to grow rapidly ( $\approx 60$ cells in $500 \mathrm{MCS}$ ). In con-

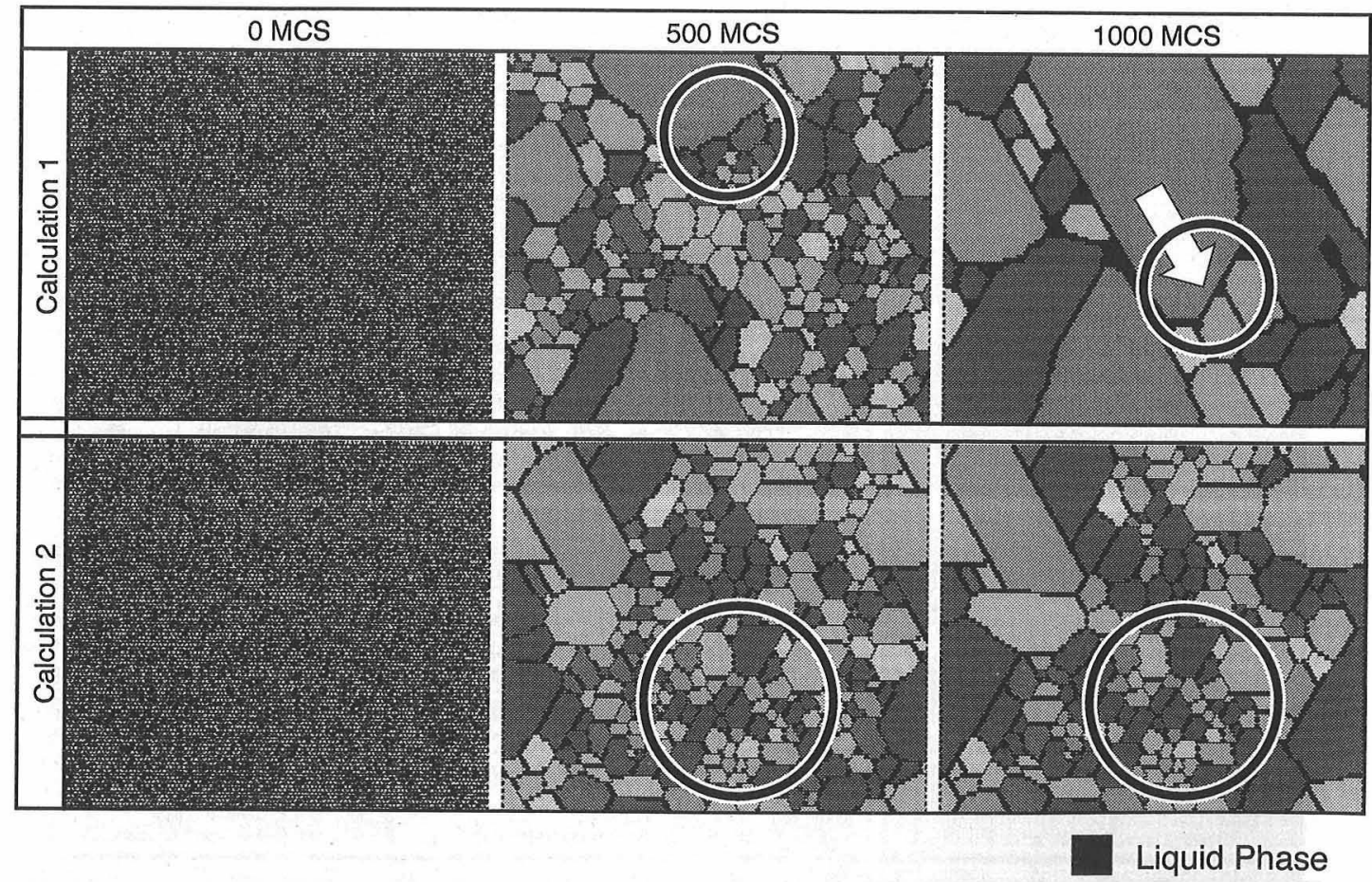

Fig. 4. Influence of liquid phase accumulation on microstructure development. When liquid phase accumulated on a growth front of a large grains, the large grain grew rapidly (calculation 1 ). 

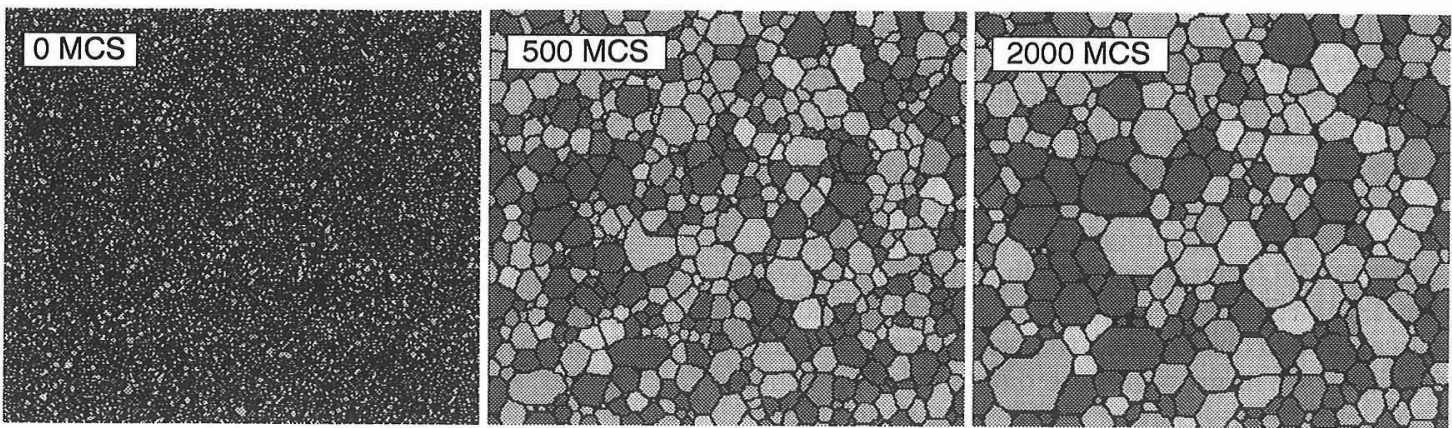

Fig. 5. Microstructure development with isotropic interface energy. The microstructure becomes uniform and no abnormally grown grain is observed.

trast, no abnormal grain growth was observed in areas where the liquid phase remained separated between a number of small grains (as indicated by the large circle).

From these results, we conclude that the accumulation of liquid phase along growth front plays an important role in the self-reinforcement phenomenon. Furthermore, it is suggested that $5 \%$ liquid phase fraction is insufficient to form continuous liquid phase layers required at the growth fronts of larger grains for them to abnormal grain growth. In $20 \%$ liquid phase fraction, almost all grains are surrounded by liquid phase cells and no grain can grow preferentially over the others. As discussed in the above, the self-reinforcement microstructures appeared only for $10 \%$ liquid phase fraction. This condition is thought to correspond to a mixture of discontinuous and continuous liquid phase layers along growth fronts.

Finally, it should be noted that although these two calculations in Fig. 4 started from identical microstructures, the final microstructures were quite different. Therefore, the final microstructures obtained do not depend critically on the initial microstructures.

\subsection{Influence of anisotropic interface energy}

Anisotropic grain growth is one of the principal characteristics of silicon nitride and is thought to be related in some way to self-reinforcement. Although the mechanism of anisotropic growth is beyond the scope of the present study, anisotropy in interface energy is one probable reason. ${ }^{11), 28)}$ Such anisotropy can be easily introduced into the Potts model.

Figure 5 shows the microstructure development for isotropic interface energy. The average grain size was somewhat larger than that for the anisotropic case. The most striking change was in the grain size distribution. The microstructure was almost uniform, quite far from abnormal grain growth. The grain size distribution (Fig. 6) was fairly sharp showing only one peak, which indicates nearly normal growth behavior.

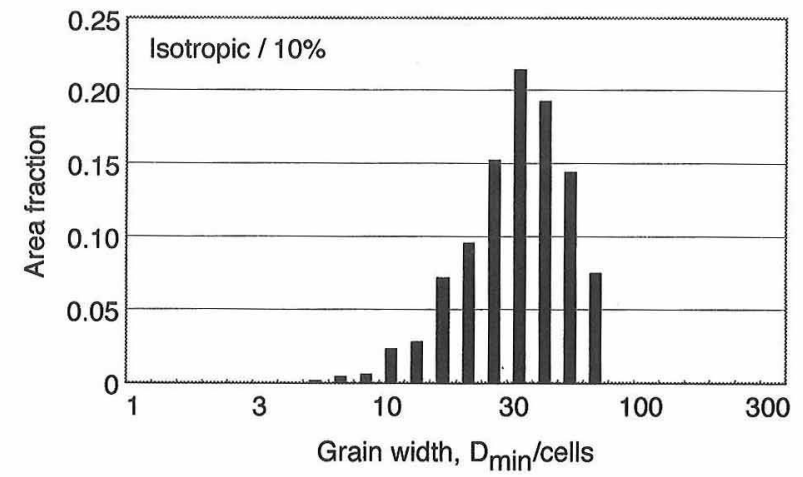

Fig. 6. Grain size distributions of isotropic interface energy. The distribution is sharp and has only one peak.

Unfortunately, a comparison between these results and actual silicon nitride is difficult, because it is almost impossible for silicon nitride to change interface energy from anisotropic to isotropic. Even so, these simulation results suggest anisotropy has a markedly strong influence on the mechanism of inhomogeneous grain growth.

3.3 Influence of mass transport at intergranular films In the previous sections, all calculations were performed using the Mode I algorithm. This is based on an assumption that the diffusion in intergranular films is as fast as that of triple junctions. Next, microstructure development under Mode II was examined. The other calculation conditions are the same as the previous calculation under Mode I, described in Section 3.1.

The microstructures of Mode II calculation are shown in Fig. 7. Preferential growth of several grains was also observed at $10 \%$ liquid phase fraction similar to that of Mode I. The microstructures of 5 and $20 \%$ liquid phase fractions were uniform and almost same as those of Mode I
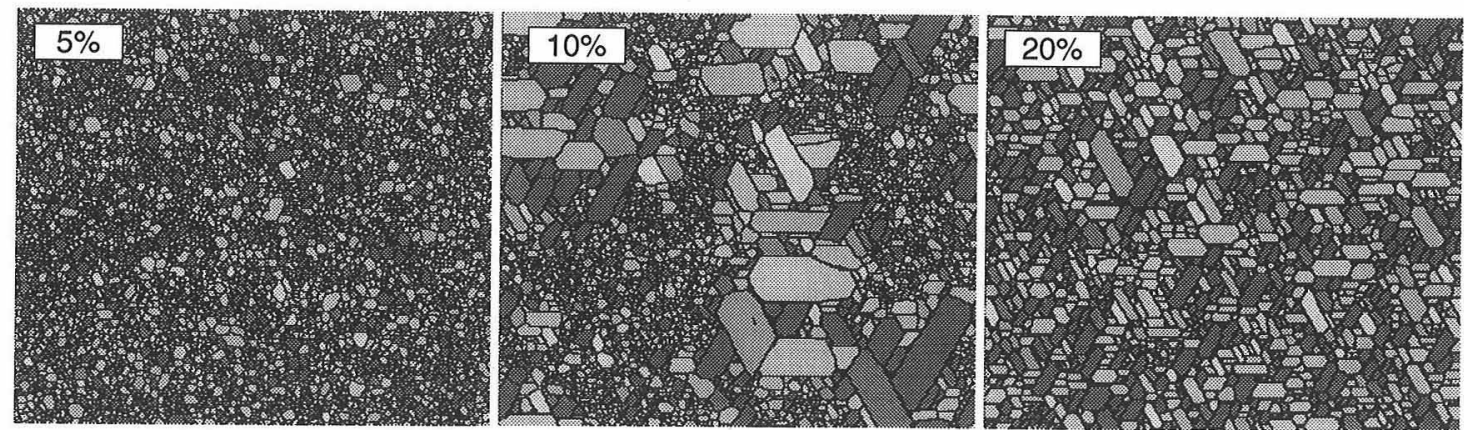

Fig. 7. Microstructures after 2000 MCS calculated under Mode II. The microstructures are similar to those of Mode I (Fig. 2). 
(Fig. 2). This results suggests that the influence of mass transport at intergranular thin film (two grains boundary) on self-reinforced microstructure was relatively small compared to the influence of liquid phase fraction or anisotropic growth.

\section{Conclusion}

A simulation model for grain growth in silicon nitride was proposed on the basis of the Potts model. The principal characteristics of silicon nitride, the presence of liquid phase and anisotropy in growth were discussed. With this simulation model, a self-reinforced structure was successfully obtained.

(1) The liquid phase fraction greatly influenced on microstructure development. The self-reinforcement phenomenon was observed only within a particular range of liquid phase fractions. At an excess or insufficient fraction, the microstructures became homogeneous. This behavior agreed well with experimental results obtained for actual materials.

(2) Anisotropy in interface energy was found to be one of the significant factors for self-reinforcement. When simulated under isotropic interface energy, the microstructure became homogeneous, in addition to a change in grain morphology from columnar to globular.

Acknowledgment This work was commissioned by NEDO as part of the Synergy Ceramics Project under the Industrial Science and Technology Frontier (ISTF) Program being by AIST and MITI, Japan.

\section{References}

1) F. F. Lange, J. Am. Ceram. Soc., 56, 518-22 (1973).

2) F. F. Lange, Am. Ceram. Soc. Bull., 62, 1369-74 (1983).

3) E. Tani, S. Umebayashi, K Kishi, K. Kobayashi and M. Nishijima, Am. Ceram. Soc. Bull., 65, 1311-15 (1986).

4) M. Mitomo and S. Uenosono, J. Am. Ceram. Soc., 75, 103-08 (1992).

5) M. Mitomo and K. Mizuno, J. Ceram. Soc. Japan (YogyoKyokai-Shi), 94, 106-11 (1986).

6) M. Hillert, Acta Metall., 13, 227-38 (1965).

7) M. P. Anderson, D. J. Srolovitz, G. S. Grest and P. S. Sahni, Acta Metall., 32, 783-91 (1984).

8) D. J. Srolovitz, M. P. Anderson, P. S. Sahni and G. S. Grest, Acta Metall., 32, 793-802 (1984).
9) G. N. Hassold, I.-W. Chen and D. J. Srolovitz, J. Am. Ceram. Soc., 73, 2857-64 (1990).

10) I.-W. Chen, G. N. Hassold and D. J. Srolovitz, J. Am. Ceram. Soc., 73, 2865-72 (1990).

11) U. Kunaver and D. Kolar, Acta Metall. Mater., 41, 2255-63 (1993).

12) Y. Takayama, T. Tozawa, H. Kato and Y. Ushiroda, J. Japan Inst. Metals, 59, 1006-12 (1995) [in Japanese].

13) D. J. Srolovitz, G. S. Grest and M. P. Anderson, Acta Metall., 34, 1833-45 (1986).

14) D. J. Srolovitz, G. S. Grest, M. P. Anderson and A. D. Rollett, Acta Metall., 36, 2115-28 (1988).

15) H. Matsubara and R. J. Brook, "Ceramic Transactions," Vol. 71 , Ed. by K. Koumoto, L. M. Sheppard and H. Matsubara, Am. Ceram. Soc., Westerville, Ohio, USA (1996) pp. 40318.

16) M. Tajika, M. Matsubara and W. Rafaniello, J. Ceram. Soc. Japan, 105, 928-33 (1997).

17) A. D. Rollett, D. J. Srolovitz and M. P. Anderson, Acta Metall., 37, 1227-40 (1989).

18) G. S. Grest, M. P. Anderson, D. J. Srolovitz and A. D. Rollett, Scripta Metall. et Mater., 24, 661-65 (1990).

19) H. Emoto and M. Mitomo, J. Eur. Ceram. Soc., 17, 797-804 (1997).

20） D. R. Clarke and G. Thomas, J. Am. Ceram. Soc., 60, 491-95 (1977).

21) L. K. V. Lou, T. E. Mitchell and A. H. Heuer, J. Am. Ceram. Soc., 61, 392-96 (1978).

22) D. R. Messier, F. L. Riley and R. J. Brook, J. Mater. Sci., 13, 1199-205 (1978).

23) C.-M. J. Hwang and T. Y. Tien, "Materials Science Forum," Vol. 47, Trans Tech Publications, Switzerland (1989) pp. 84-109.

24) Y. Iwamoto, S. G. Shin and H. Matsubara, "Ceramic Transactions," Vol. 71, Ed. by K. Koumoto, L. M. Sheppard and H. Matsubara, Am. Ceram. Soc., Westerville, Ohio, USA (1996) pp. 483-90.

25) A. J. Pyzik and D. R. Beaman, J. Am. Ceram. Soc., 76, 273744 (1993).

26) C.-M. J. Hwang, T. Y. Tien and I.-W. Chen, "Sintering '87," Ed. by S. Sōmiya, M. Shimada, M. Yoshimura and R. Watanabe, Elsevier Science Publishers, Essex, UK (1988) pp. 1034-39.

27) H. Björklund, L. K. L. Falk and J. Wasén, "Key Engineering Materials," Vol. 89-91, Trans Tech Publications, Switzerland (1994) pp. 477-82.

28) A. H. Heuer, G. A. Fryburg, L. U. Ogbuji, T. E. Mitchell and S. Shinozaki, J. Am. Ceram. Soc., 61, 406-12 (1978). 